\title{
Investigation on Musculoskeletal Symptoms and Ergonomic Risk Factors at Metal Stamping Industry
}

\author{
Mean Vathna ${ }^{1, a}$, Nor Suliani Abdullah ${ }^{2, b}$, Siti Zawiah Md Dawal ${ }^{2, c}$, \\ Hideki Aoyama ${ }^{3, \mathrm{~d}}$ and Kruy Sothea ${ }^{4, e}$ \\ ${ }^{1,2}$ Department of Mechanical Engineering, Faculty of Engineering, University of Malaya,50603 \\ Kuala Lumpur,Malaysia \\ ${ }^{3}$ Department of Mechanical Engineering, Faculty of Science and Technology, KEIO University, 3- \\ 14-1 Hiyoshi, Kohoku-Ku, 233-8522, Japan \\ ${ }^{4}$ Department of Industrial and Mechanical Engineering, Institute of Technology of \\ Cambodia,Russian Confederation Boulevard, P.O. Box 86, Phnom Penh, Cambodia \\ avathna_mean@yahoo.com, bn_suliani@yahoo.com, csitizawiahmd@um.edu.my, \\ haoyama@sd.keio.ac.jp, ${ }^{e}$ kruysothea@gmail.com
}

Keywords: Manual Handling, Musculoskeletal Disorder (MSD), Ergonomic Risk Factors

\begin{abstract}
.
The objective of the study is to identify the symptoms ofmusculoskeletal disorder (MSD) and ergonomic risks on manual handling task at a metal stamping company. Data were collected using Cornell Musculoskeletal Discomfort Questionnaire (CMDQ) and the Rapid Upper Limb Assessment (RULA). The results revealed that there were significant relationships between selfreported pain and RULA posture scores on the trunk and neck regions with reference to MSD symptoms. Further, the results of RULA score also indicated high risk posture level on the task being investigated.
\end{abstract}

\section{Introduction}

Manual handling is any activityrequiring the use of force exerted by a human to lift, lower, push, pull, carry or otherwise move, hold or restrain any animate or inanimate object. It is a major activity of all workplaces where manual task are required. However, those manual handling tasks have their degrees of limitation; thus if the tasks are not correctly managed, there will be pains or discomforts occuron body regions and consequently, these will lead to serious injuries.

The serious injuries that are often caused by this job are commonly related to disorders, especially low back disorders.A study by NIOSH (1997) onmusculoskeletal disorders (MSDs)stated that the rates of frequency and severity of these injuries considerably increase when objects arehuge, heavy, have poor handle or when frequently lifting is required[1].It is agreed that these degenerative and inflammatory conditions are considered as MSDs[2], which normallyhave influenceon the body regions including low back, neck, shoulder, forearm, and hand [3].

TheMSD injuries due to manual lifting tasks in the workplace not only significantly reduce the workers' life quality, but also have a huge impact on economic decrease of the whole organizations or enterprises. Obviously, in the United states, $29 \%$ of the injuries and illnesses requires a median of 10 days for sick leave due to the impact of work-related musculoskeletal disorder (WMSD) [4]. Additionally, the compensation costs, lost wages, and lost productivity caused by WMSD, is annually between $\$ 45$ and $\$ 54$ billion [5]. Regarding to this actual cost, the WMSDs impact is absolutely enormous especially if corporate economics is considered.

The MSDs risk factors are frequently caused by physical job features such as repetitive work [610], work in extreme and static postures [8, 11, 12] and work with forceful arm and hand movements [13-15], which have been found to be associated with upper extremity disorders. Likewise, heavy lifting and forceful movements have also been found to be the cause of low back disorders [16], while another risk factor is on working in a forward bent position [17]. 
In Malaysian industries, manual tasks using human labor such as lifting, loading and unloading are still widely used in production process due to highly flexible and cheap labors. However, most of the industrial workers are exposed to repetitive task, prolonged work and pain because of awkward postures that often lead to muscle fatigue and musculoskeletal discomfort among those workers. Thus, the aim of this study is to determine the musculoskeletal symptoms and ergonomic risks present during loading and unloadingtask in ametal stamping company.

\section{Material and Methods}

Subjects.Seven participants involved in the study are all males, whomainly do handling work, particularly at laser cutting workstation in a metal stamping company, as their major tasks and have no previous history of musculoskeletal injuries. The mean age of the employees is $23 \pm 1.59$ years, mean weight is $65.14 \pm 8.44 \mathrm{~kg}$, mean height of employees is $167.43 \pm 5.26 \mathrm{~cm}$, and mean year of workingis $11.86 \pm 5.41$ years.

Use of Cornell Musculoskeletal Disorder Questionnaire (CMDQ).Data were collected by distributing the Cornell Musculoskeletal Disorder Questionnaire (CMDQ) [18]to all the participants. Each questionnaire contains 54 items to be answered including a body map-diagram and questions related to the prevalence of musculoskeletal ache, pain, or discomfort in 18 regions of the body, (including neck, shoulders, upper back, upper arm, lower back, forearm, wrists, hips/buttocks, thighs, knees, lower legs and feet). The participants wereexpected to indicate the frequency of discomfort on an ordinal scale from 0 (never) to 10 (several times every day) and severity of discomfort from 1 (slightly uncomfortable) to 3 (very uncomfortable). A pain level of at least "moderately uncomfortable" was selected as a severity threshold for determining prevalence and frequency. The level at which the discomfort interfered with work was scored from 1 (no interference) to 3 (substantial interference).Total discomfort score was calculated by using the formula: discomfort score $=$ frequency of discomfort $\times$ severity of discomfort $\times$ discomfort interference

RULA.The handling posture adopted by each operator was evaluated using the Rapid Upper Limb Assessment (RULA) [19]. A digital video camera was used to record and to capture posture of the operatorswhile working.According to this method, postures of each body part were given a score after analysis. The most neutral or best posture is indicated by a score of 1 . This means that neck in $10^{\circ}$ flexion, up straight trunk, by side arms, $90^{\circ}$ elbows flexion, forearms in between midway prone and supinate, neutral wrist position; and well supported legs. The worst position is indicated by a score of 4 (e.g. trunk flexion above $60^{\circ}$ or between $20^{\circ}$ to $60^{\circ}$ with twisting or side bending). To summarize, the total grand score for RULA is a score of 7 . This grand score reflect the working's posture associated with the musculoskeletal loading. Grand score of 1 or 2 showed that the working posture is acceptable. Higher grand score, actions are suggested for workstation improvement such as further investigation and changes required if grand score is 3 or 4, grand score of 5 or 6 suggests that prompt investigation and changes are needed; and grand score of 7 showed that immediate investigations and changes are required.

Validation of RULA and CMDQ. The results from RULA and CMDQ were validated using Chi-square $\left(\chi^{2}\right.$-test $)$ to verify whether the individual score of each body region was significantly related to the self-reported pain.Pains or discomforts presented in the CMDQ surveywas considered as pain, which is "yes", and the absence of pain or discomfort was recorded as no pain, which is "No".RULA posture score was classified into two categories, which is posture score equal to 1 (score 1) and posture score higher than 1 (score $>1$ ). Thus, the testing consisted of two independent variables, which wereRULA posture score of each body region ("score 1" and "score $>1$ ") and discomforts or pains ("Yes" and "No") from CMDQ. 


\section{Result}

Body Discomfort Survey. The result in Table 1shows that male operators working on the laser cutting workstation felt discomfort, mostly at the lower back $(52.79 \%)$, both forearms $(11.36 \%)$, both wrists $(4.57 \%)$ and both upper arms (3.61\%), while it was less pronounced in the neck $(0.005 \%)$, hip and both thighs $(0.01 \%)$, both knees $(0.06 \%)$ and both lower legs $(0.14 \%)$. There was also slight discomfort feeling on both feet $(0.85 \%)$, both shoulders $(1.80 \%)$ and upper back $(2.40 \%)$.

Table 1. Result of body discomfort by CMDQ

\begin{tabular}{|c|c|c|c|c|c|c|}
\hline \multicolumn{2}{|c|}{ Body region } & Frequency & Discomfort & Interference & $\begin{array}{l}\text { Discomfort } \\
\text { score }\end{array}$ & $\%$ \\
\hline \multicolumn{2}{|l|}{ Neck } & 1.5 & 1 & 1 & 1.5 & 0.005 \\
\hline \multirow{2}{*}{ Shoulder } & (Right) & 15.5 & 5 & 7 & 542.5 & 1.802 \\
\hline & (Left) & 15.5 & 5 & 7 & 542.5 & 1.802 \\
\hline \multicolumn{2}{|l|}{ Upper Back } & 15 & 6 & 8 & 720 & 2.391 \\
\hline \multirow{2}{*}{ Upper Arm } & (Right) & 17 & 8 & 8 & 1088 & 3.613 \\
\hline & (Left) & 17 & 8 & 8 & 1088 & 3.613 \\
\hline \multicolumn{2}{|l|}{ Lower Back } & 55 & 17 & 17 & 15895 & 52.787 \\
\hline \multirow{2}{*}{ Forearm } & (Right) & 28.5 & 10 & 12 & 3420 & 11.358 \\
\hline & (Left) & 28.5 & 10 & 12 & 3420 & 11.358 \\
\hline \multirow{2}{*}{ Wrist } & (Right) & 17 & 9 & 9 & 1377 & 4.573 \\
\hline & (Left) & 17 & 9 & 9 & 1377 & 4.573 \\
\hline \multicolumn{2}{|c|}{ Hip/Buttocks } & 1.5 & 1 & 2 & 3 & 0.01 \\
\hline \multirow{2}{*}{ Thigh } & (Right) & 1.5 & 1 & 2 & 3 & 0.01 \\
\hline & (Left) & 1.5 & 1 & 2 & 3 & 0.01 \\
\hline \multirow{2}{*}{ Knee } & (Right) & 5 & 2 & 2 & 20 & 0.066 \\
\hline & (Left) & 5 & 2 & 2 & 20 & 0.066 \\
\hline \multirow{2}{*}{ Lower Leg } & (Right) & 4.5 & 3 & 3 & 40.5 & 0.135 \\
\hline & (Left) & 4.5 & 3 & 3 & 40.5 & 0.135 \\
\hline \multirow{2}{*}{ Foot } & (Right) & 8.5 & 6 & 5 & 255 & 0.847 \\
\hline & (Left) & 8.5 & 6 & 5 & 255 & 0.847 \\
\hline
\end{tabular}

RULA.Figure 1 shows the comparison of the RULA mean score with the maximum score of RULA. The mean for trunk body region was equal to $4.43(73.81 \%)$ which was quite significant if comparing to maximum score of 6 , while there is slightly significant for the mean score of neck, $1.86(30.95 \%)$. This signified that the necks and the trunk of the participants were in twisting or side bending position while operating the task. Meanwhile, the mean of lower arms is $1.93(64.29 \%)$ compared to the maximum score of 3 , while the upper arm is equal to $2.71(45.24 \%)$. This demonstrated that the lower arms were in flexion less than $60^{\circ}$ and up to $100^{\circ}$ and the upper arms were in flexion between $45^{\circ}$ to $90^{\circ}$ or in flexion between $20^{\circ}$ to $45^{\circ}$ with their shoulders raising or upper arms were abducted. For the wrist mean score of $2.92(45.24 \%)$ with the maximum of 6 showed that the wrists were in flexion degree up to $15^{\circ}$ with bending away from the midline or the degree of flexion was above $15^{\circ}$ in operation. The mean leg score was $1.71(85.71 \%)$ with a maximum score of 2 . This also indicated that the position of the legs in the observation was in an evenly balanced posture or the legs were not well supported. 
As shown in Table 2, the mean of the RULA grand score was 7 which showed that the operators' workstations have to be investigated further and changesshould be effected immediately. Furthermore, based on the result of action level, there were no participants in the laser cutting workstation who could achieve a level 1 or 2 , which is an acceptable posture level among the 4 action levels of the RULA analysis tool.

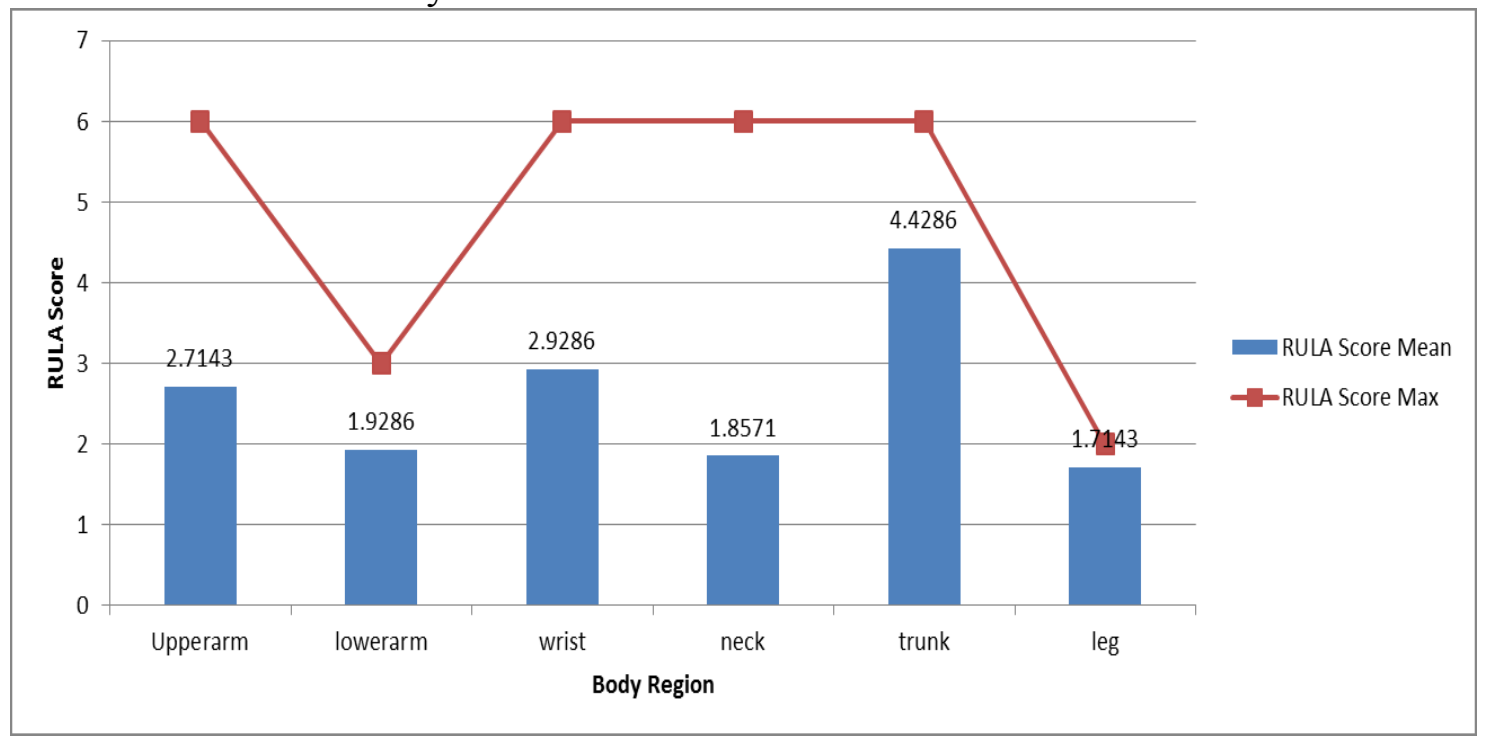

Fig.1. Comparison of the RULA mean score with the maximum score of RULA

Table 2. RULA Grand Score and Action Level

\begin{tabular}{|cl|c|c|}
\hline \multicolumn{1}{|c|}{ RULA Result } & Action Level & Grand Score \\
\hline \multirow{2}{*}{ Total } & Mean & 4 & 7 \\
& Std. Deviation & 0 & 0 \\
\hline
\end{tabular}

Validation on RULA and CMDQ.Table 3 shows the results of validation on RULA and CMDQ. The score $>1$ of trunk posture was $85.71 \%$ for the operators, while pain or discomfort on the trunkhadthe same result of $85.71 \%$; and yielded a strongly significant $\left(\chi^{2}=7\right.$ and $\left.p=0.008\right)$ relationship between self-reported pain and trunk score. Similarly, the lower arm score was $>1$ in $71.43 \%$ of the total participants, while the self-reported pain was also $71.43 \%$, which also yielded a significant $\left(\chi^{2}=7\right.$ and $\left.p=0.008\right)$ relationship between the lower arm score and the self-reported pain.

The posture score of upper arm was $>1$ in $85.71 \%$ of operators corresponding to self-reported pain of $57.14 \%$ and the correlation between the two results was $\chi^{2}=1.556(p=0.212)$, which is higher than the significance level of 0.05 . Thus, there was no significant association between the self-reported pain and the score of upper arm. Likewise, the wrist posture score of higher than 1 in $85.71 \%$ of operators while the self-reported pain was $71.43 \%$ with the result with non-significant $\left(\chi^{2}=0.467, p=0.495\right)$ relationship between both result. Similarly, there were no significant relationship $\left(\chi^{2}=0.194\right.$ and $0.058, p=0.659$ and 0.809$)$ between neck or leg scores respectively and reported pain.

\section{Discussion}

The aim of the study is to identify the MSD symptoms and ergonomic risks in manual handling operators whose task is to lift stamped metal part for loading and unloading in and out of laser cutting machine in a metal stamping company, in Malaysia.

The result of this study indicated that the 7 male operators, who performed manual lifting tasks of loading and unloading stamped metal in the laser cutting workstation, experienced symptoms of 
musculoskeletal disorder and ergonomic risks caused by their awkward working postures and unsuitable workstations.

The same study conducted byM. Massaccesi, et al.[20], the prevalence of MSD symptom was found to be $65 \%$, while other study found $50-55 \%$ of MSD prevalence was found byB. Çivitci, M. Uçar, A. Inanır, and S. Çivitci[21]. Additionally, a study conducted byP. Wang, D. Rampel, R. Harrison, J. Chan, and B. Ritz[22], the prevalence of MSD symptom was 58\%, while a study conducted byA. Kaergaard and J. H. Andersen[23] was 14.4\%. Another study byD. Ranney, R. Wells, and A. Moore[24] found 54\% of 146 female workers had musculoskeletal disorders symptom in the trunk that potentially caused by work-related.

In the relevant literature, due to the awkward working postures, the body regions with the most suffered by MSD problems are concerned as the trunk, upper back, lower back, neck, shoulders, and upper limbs [20]. Similarly, the results from this study also supports the result of the previous finding that the most significant areas with MSD symptoms were in the trunk and the lower arm.

Therefore, the results of the study indicated that worker are experiencing or suffering pains on their trunk and lower arm regions that can be considered as MSD symptoms, which caused by awkward working postures and unsuitable workstation design.

Table 3. RULA Validation resultsof body-part score and number of operator reporting pain or discomfort in each body region (by $\left(\chi^{2}\right.$-analysis) with significant level 0.05 )

\begin{tabular}{|c|c|c|c|c|c|}
\hline \multicolumn{4}{|c|}{ Laser Cutting Operators } & \multicolumn{2}{|c|}{$\chi 2$-Test Result } \\
\hline \multirow{2}{*}{ Body Part } & \multirow{2}{*}{ Pain } & \multicolumn{2}{|c|}{ Posture Score } & \multirow{2}{*}{$\chi^{2}$} & \multirow{2}{*}{$\boldsymbol{P}$} \\
\hline & & 1 & $>1$ & & \\
\hline \multirow{2}{*}{ Neck } & Yes & 0 & 1 & \multirow{2}{*}{0.194} & \multirow{2}{*}{0.659} \\
\hline & No & 1 & 5 & & \\
\hline \multirow{2}{*}{ Trunk } & Yes & 0 & 6 & \multirow{2}{*}{7} & \multirow{2}{*}{0.008} \\
\hline & No & 1 & 0 & & \\
\hline \multirow{2}{*}{ Upper Arm } & Yes & 0 & 4 & \multirow{2}{*}{1.556} & \multirow{2}{*}{0.212} \\
\hline & No & 1 & 2 & & \\
\hline \multirow{2}{*}{ Lower Arm } & Yes & 0 & 5 & \multirow{2}{*}{7} & \multirow{2}{*}{0.008} \\
\hline & No & 2 & 0 & & \\
\hline \multirow{2}{*}{ Wrist } & Yes & 1 & 4 & \multirow{2}{*}{0.467} & \multirow{2}{*}{0.495} \\
\hline & No & 0 & 2 & & \\
\hline \multirow{2}{*}{ Legs } & Yes & 1 & 2 & \multirow{2}{*}{0.058} & \multirow{2}{*}{0.809} \\
\hline & No & 1 & 3 & & \\
\hline
\end{tabular}

\section{Conclusion}

There were significant relationships between the results of CMDQ and RULA in body regions at trunk and lower arm. Furthermore, these MSD assessment methods, which areCMDQ, RULA and Chi-square test for RULA validation, provide a promising investigation and evaluation results.

\section{Acknowledgements}

This work was financially supported by the ASEAN UNIVERSITY NETWORK / Southeast Asia Engineering Education Development Network (AUN/SEED-Net)and the Fundamental research Grant Scheme (FRGS), under the project number FP023-2012A. 


\section{Reference}

[1] B. Bernard, "Musculoskeletal disorders and workplace factors. DHHS (NIOSH) Publication No. 97-141," Cincinnati, OH: US Department of Health and Human Services, 1997.

[2] P. W. Buckle and J. Jason Devereux, "The nature of work-related neck and upper limb musculoskeletal disorders," Applied ergonomics, vol. 33, pp. 207-217, 2002.

[3] L. Punnett and D. H. Wegman, "Work-related musculoskeletal disorders: the epidemiologic evidence and the debate," Journal of Electromyography and Kinesiology, vol. 14, pp. 13-23, 2004.

[4] BLS, "Nonfatal occupational injuries and illness requiring days away from work for state government and local government workers," In: Economics Release (Ed.), U.S. Department of Labor, Feb 24th ed., p. 7, 2011.

[5] K. K. Dunning, K. G. Davis, C. Cook, S. E. Kotowski, C. Hamrick, G. Jewell, and J. Lockey, "Costs by industry and diagnosis among musculoskeletal claims in a state workers compensation system: 1999-2004," American journal of industrial medicine, vol. 53, pp. 276-284, 2010.

[6] H.-C. Chiang, Y.-C. Ko, S.-S. Chen, H.-S. Yu, T.-N. Wu, and P.-Y. Chang, "Prevalence of shoulder and upper-limb disorders among workers in the fish-processing industry," Scandinavian journal of work, environment \& health, pp. 126-131, 1993.

[7] K. Ekberg, B. Björkqvist, P. Malm, B. Bjerre-Kiely, M. Karlsson, and O. Axelson, "Casecontrol study of risk factors for disease in the neck and shoulder area," Occupational and Environmental Medicine, vol. 51, pp. 262-266, 1994.

[8] K. Ohisson, R. Attewell, B. Pålsson, B. Karlsson, I. Balogh, B. Johnsson, A. Ahlm, and S. Skerfving, "Repetitive industrial work and neck and upper limb disorders in females," American journal of industrial medicine, vol. 27, pp. 731-747, 1995.

[9] N. Onishi, H. Nomura, K. Sakai, T. Yamamoto, K. Hirayama, and T. Itani, "Shoulder muscle tenderness and physical features of female industrial workers," Journal of human ergology, vol. 5, p. 87, 1976.

[10] A. M. Rossignol, E. P. Morse, V. M. Summers, and L. D. Pagnotto, "Video display terminal use and reported health symptoms among Massachusetts clerical workers," Journal of Occupational and Environmental Medicine, vol. 29, pp. 112-118, 1987.

[11] Å. Kilbom, J. Persson, and B. G. Jonsson, "Disorders of the cervicobrachial region among female workers in the electronics industry," International Journal of Industrial Ergonomics, vol. 1, pp. 37-47, 1986.

[12] L. Punnett, L. J. Fine, W. M. Keyserling, G. D. Herrin, and D. B. Chaffin, "Shoulder disorders and postural stress in automobile assembly work," Scandinavian journal of work, environment \& health, pp. 283-291, 2000.

[13] A. AARÅs and E. STRANDEN, "Measurement of postural angles during work," Ergonomics, vol. 31, pp. 935-944, 1988.

[14] K. B. Veiersted, "Sustained muscle tension as a risk factor for trapezius myalgia," International Journal of Industrial Ergonomics, vol. 14, pp. 333-339, 1994.

[15] E. Viikari-Juntura, H. Riihimäki, S. Tola, T. Videman, and P. Mutanen, "Neck trouble in machine operating, dynamic physical work and sedentary work:. A prospective study on occupational and individual risk factors," Journal of clinical epidemiology, vol. 47, pp. 1411-1422, 1994. 
[16] L. Punnett, L. J. Fine, W. M. Keyserling, G. D. Herrin, and D. B. Chaffin, "Back disorders and nonneutral trunk postures of automobile assembly workers," Scandinavian journal of work, environment \& health, pp. 337-346, 1991.

[17] E. Vingård, L. Alfredsson, M. Hagberg, Å. Kilbom, T. Theorell, M. Waldenström, E. W. Hjelm, C. Wiktorin, and C. Hogstedt, "To What Extent Do Current and Past Physical and Psychosocial Occupational Factors Explain Care-Seeking for Low Back Pain in a Working Population?: Results from the Musculoskeletal Intervention Center-Norrtälje Study," Spine, vol. 25, pp. 493-500, 2000.

[18] A. Hedge, "Cornell Musculoskeletal Discomfort Questionnaires (CMDQ)," ed, 1999.

[19] L. McAtamney and E. Nigel Corlett, "RULA: a survey method for the investigation of work-related upper limb disorders," Applied ergonomics, vol. 24, pp. 91-99, 1993.

[20] M. Massaccesi, A. Pagnotta, A. Soccetti, M. Masali, C. Masiero, and F. Greco, "Investigation of work-related disorders in truck drivers using RULA method," Applied ergonomics, vol. 34, pp. 303-307, 2003.

[21] B. Çivitci, M. Uçar, A. Inanır, and S. Çivitci, "Research for neck and upper extremities problems among the sewing machine operators. Poster presented at the10th International Participation Ergonomic Congress, Bursa, Turkey.," 2004.

[22] P. Wang, D. Rampel, R. Harrison, J. Chan, and B. Ritz, "Work-organizational and personal factors associated with upper body musculoskeletal disorders among sewing machine operators. Occupational and Environmental Medicine," 2007.

[23] A. Kaergaard and J. H. Andersen, "Musculoskeletal disorders of the neck and shoulders in female sewing machine operators: prevalence, incidence, and prognosis," Occupational and Environmental Medicine, vol. 57, pp. 528-534, 2000.

[24] D. Ranney, R. Wells, and A. Moore, "Upper limb musculoskeletal disorders in highly repetitive industries: precise anatomical physical findings," Ergonomics, vol. 38, pp. 14081423, 1995. 